\title{
Assessment of the sustainability of concrete by ensuring per- formance during structure service life
}

\author{
Dan Georgescu ${ }^{1}$, Radu Vacareanu ${ }^{1}$, Alexandru Aldea ${ }^{1}$, Adelina Apostu $^{1}$, Cristian Arion ${ }^{1 *}$, Andrei Girboveanu ${ }^{1}$ \\ 1 Technical University of Civil Engineering Bucharest; dan.georgescu@utcb.ro \\ * Correspondence: cristian.arion@utcb.ro
}

\begin{abstract}
The article presents an original method to assess the sustainability of concrete. The method uses three parameters, namely: performance, lifetime and environmental impact, to calculate a sustainability index. The originality and the simplicity of the proposed method presented in the article consists in the fact that by applying the relation to determine the sustainability index, the first two factors service life and performance are constant. This approach is possible in the context of the new proposals to specify the durability of structural concrete in EN 1992 and EN 206. That allows classification of concrete according to its performance, through Environmental action Resistance Classes (ERC). For this purpose, specific experimental methods were used in order to determine the performance of concrete exposed to carbonation. The concretes were prepared with two cement types with additions (CEM II / A-S and CEM II / A-M (S-LL)). Based on the carbonation resistance classes (the first constant - the performance) and exposure classes, the thickness of the concrete cover layer was determined to ensure a certain service lifetime (second constant - the service lifetime). Finally, the global warming potential was calculated for each composition, consequently allowing the users of the method, to select the compositions with the lowest impact on the environment.
\end{abstract}

Keywords: sustainability; concrete; assessment; performance; service life; environment.

\section{Introduction}

Sustainability is a general concept based on three dimensions: ecological, economical, and socio-cultural. This concept, simultaneously and holistically deals with these requirements which have a different impact on sustainability. New trends in sustainability are clearly ecologically-oriented (Figure 1, strong sustainability) are also the main target for our proposal presented in this article, to assess the sustainability of concrete. [1]
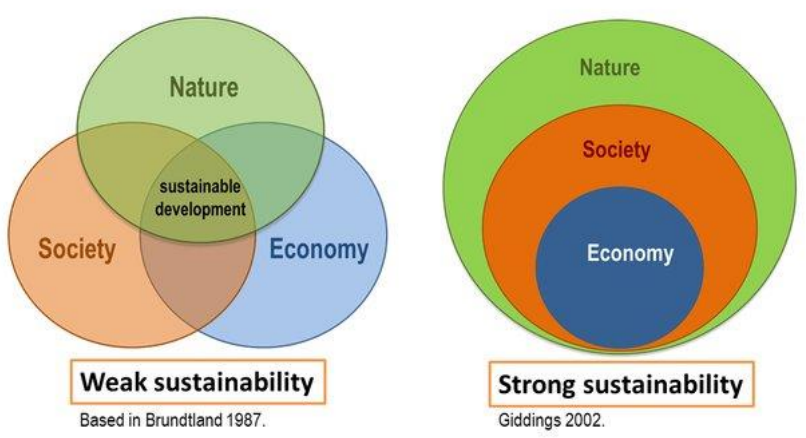

Figure 1. Sustainability pillars [1]

On the one hand, it is obvious that currently we are strongly feeling the climate change and the building sector has an important "contribution". On the other hand, it would be incomplete to analyze constructions exclusively through their environmental impact. The method presented in this article aims for a more objective approach, related 
to the revision proposals of the European reinforced concrete standards. In this way, new paths of addressing an important and topical field can be opened.

Regarding the situation in Romania, we consider as the best example, the indirect mentions related to sustainability in Law no. 177/2015 [2] with the last amendments and completions of Law no. 10 (the Romanian building quality law published in the official Gazette of Romania) on quality in construction. This specifies the basic requirements of constructions, mainly related to hygiene, health and the environment, energy saving and sustainable use of natural resources. In this law there are no unitary approaches on sustainability or guidelines to quantify and link such requirements, leading to an impossible enforcement of the law. Obviously, in the not-too-distant future, sustainability would become an important requirement for reinforced concrete structures. Of course, in this case, an approach that can quantify this requirement will be needed, as it happens with other fundamental requirements. That would be through considering:

- The sustainability in the design of reinforced concrete elements and structures;

- The implementation of a system to classify reinforced concrete buildings from a sustainability perspective, based on indicators that are not related only to the environmental impact;

- The development of a tool to assess sustainability at different levels of the reinforced concrete such as: materials, elements and structures;

- The optimization of the choice of materials / solutions / technologies to meet the requirements related to sustainability.

The method presented in the present article is a proposal to quantify the sustainability potential of concrete. As far as reinforced concrete structures are concerned, presently, their behavior over time is referred in terms of durability, but this is naturally related to environmental or economical aspects.

Ensuring the durability of reinforced concrete structures is no longer strictly related to maintaining some of the concrete properties when exposed to different environments but has acquired a global importance related to the sustainability of the built environment. Excessive consumption of materials needed for repair works, the need to adapt and optimize formulations, the negative effects on the environment through $\mathrm{CO} 2$ emissions and the large amount of energy needed to produce concrete, especially cement and last not least the need to ensure the same service life of buildings, regardless of the type of component materials used, have led to the need of developing a different approach to assess the sustainability of concrete.

This approach was also imposed by the need of expanding the utilisation of blended cements, which obviously have a lower environmental impact. In the current norms, whether we are talking about the unified European [3] or the national ones, there are practically no differences regarding the requirements for the concrete formulations depending on cement type. The only thing that is specified in the national norms is related to the possibility of using a certain type of cement in one field / environment or another. The use of the same concrete formulations, i.e., W/C ratio, regardless of the cement type used, leads to different performances to environmental actions and implicitly to different service lifetimes (i.e. for the same $\mathrm{W} / \mathrm{C}$ ratio, concretes prepared with different cements types have different carbonation depths, and consequently, service lifetimes of reinforced concrete constructions built with these concretes are different). In addition, there is also a lack of coherence of the provisions in different countries

Considering the need for a unitary approach, at European level a performance method is proposed to characterize the durability of concrete, through environmental Exposure Resistance Classes (ERC) [4], [5], [6], [7]. This approach will represent an alternative to the current descriptive one and will be present in the European regulations that concern reinforced concrete.

In [4], the concept of environmental resistance class is presented in detail (for the first time), as a new method to specify the durability of structural concrete, method imple- 
mented in the EN 1992 and EN 206 (CEN documents prepared by Joint Working Committee consisting of TC 104 / SC1 and CEN TC 250 / SC2, of which the first author of this article was a member).

The definition of the exposure resistance classes should be performance based, that will allow a technology development without a need to amend the classes. The definition should also be related to exposure conditions defined in the system of exposure classes, and with requirements corresponding to realistic requirements while not necessarily being the final ones. This would allow use of experience and observations from practice, to calibrate the requirements, and to adjust concrete specifications in accordance with observations from real structures under normal service conditions. The requirement for Carbonation Resistance Classes should be related to long term exposure, Exposure Class XC3, while Chloride Resistance Class should be related to Exposure Class XS2 as these are stable over time and can also be simulated with long term tests in laboratories. The exposure Class XC3 gives the conditions where the rate of carbonation is relatively high and conditions where the rate of corrosion is not insignificant. Given that the end of life used in the calibration deriving minimum cover requirements is defined as carbonation reaching the reinforcement causing depassivation/start corrosion XC3 exposure produces worse conditions than $X C 4$ with respect to carbonation rate. The higher relative humidity in concrete exposed to XC4 means, however, that it will carbonate at a rate that is slower than in XC3, but start to corrode more quickly [4]. The definition and method of determining the carbonation resistance class are given in section 3 of the paper.

The current generation of European standards for concrete contain a descriptive system of requirements (e.g. specification of maximum water / cement ratio, minimum cement content, minimum thickness of the concrete cover, etc.) and classes (e.g. exposure classes, consistency classes, compressive strength classes) to describe the performance (durability) of concrete.

This system has some significant limitations in terms of durability when it is necessary to use new construction materials without having experience of their long-term use (e.g. new cements), or in ensuring the same service life, etc.

Exposure resistance class (ERC) is a scientifically based concept that can be applied to determine the cement type areas of use, optimizing the concrete mix according to the exposure class and therefore is an effective source of $\mathrm{CO}_{2}$ emission limitation. It creates the possibility to determine the water/cement ratio, the thickness of the concrete cover layer depending on cement type, in order to achieve equal performance over the service life of the structures.

The application of the ERC concept allows the classification of concrete through the resistance classes to environmental actions, thus ensuring the same performance, a fundamental element in the application of the proposed method.

\section{General Presentation of the Concept}

\subsection{General considerations}

At European level, there are special concerns for the field of sustainability, both in unified European regulations and national strategies developed by EU countries, but also in academic and research community. Once recent academic example is that within the European University for Smart Urban Coastal Sustainability EU-CONEXUS there is a course dedicated to this topic within the Minor "Coastal Development and Sustainable Maritime Tourism", entitled "Sustainable Built Environment".

European Committee for Standardization (CEN) developed regulations that cover the case of new and existing constructions, all types of buildings, and introduce the integrated performance of buildings throughout the life cycle. Number of standards address this issue, for constructions and construction products in terms of environmental, economic and social performance. Within these unified European regulations, standards that must deal with the structural / technical or functional performances of the constructions are sketched, but not yet elaborated. Some countries in the European Union have clear strategies in this field and have developed their own guidelines and systems to assess 
sustainability [8], [9]. Also, there are internationally recognized initiatives for the classification of constructions from the sustainability perspectives that classify constructions, for example BREEAM [10] in the United Kingdom or DGNB [11] in Germany.

The sustainability of constructions is regarded and presented most of the time in a somewhat simplistic way, often only from an ecological or energy efficiency point of view. The more complex approaches that analyse holistically and multi-dimensionally the pillars of sustainability are almost exclusively based on environment, economy and sociocultural aspects.

At European level, there are approaches that are close to the method proposed in this article, related to the association and interconnection between performance, service life and environmental impact [12], [13] which refer, in particular, to reinforced concrete or the design method developed by Joint Research Center at the EC [14].

In [12] and [13] Muler et al., proposed a method to assess sustainability by calculating an Building Material Sustainability Potential index:

$$
\text { Building Material Sustainability Potential }=\frac{\text { Service Life } \times \text { Performance }}{\text { Environnemental Impact }}
$$

In this approach, the authors used different types of materials and formulations, obtaining different performance levels for the compressive strengths. Furtherly, they determined the service life time by a probabilistic approach, based on the carbonation depth and the environmental impact.

The fundamental difference between the method proposed in this article and the one in [12] and [13] is that in this case, the performance and the service life time are constant, and the calculation of the sustainability index for different types of materials/formulations results in the determinations of the environmental impact.

The design method developed by Joint Research Center at the EC [14] is a sustainable structural design (SSD) methodology having as essential parameters the environmental and structural performance during a life time. Emphasis is placed on associating the results of the environmental analysis with the performance analysis, which is treated in a probabilistic manner by introducing a simplified method of performance-based assessment. Finally, a global assessment parameter is calculated based on environmental costs, structural rehabilitation costs and financial losses resulting from disruptions in use, which allows different categories of stakeholders to make objective and informed decisions.

The originality of the method proposed in the present article consists in a simplified but not simplistic analysis of sustainability having an impact on the environment, service life and structural performance, strictly related to the specific regulations for reinforced concrete. Sustainability analysis can thus be performed on three levels, for concrete as a material in itself, for reinforced concrete elements and for structures. In this article, the sustainability assessment is exemplified for reinforced concrete as a structural material.

\subsection{Principles and stages of the method}

The method makes a connection between these steps:

1. SERVICE LIFE

2. PERFORMANCE

3. ENVIRONMENTAL IMPACT

The application steps are as follow:

1. Service Life determination. This will be considered in accordance with the specific regulations, 50 or 100 years. Probabilistic methods can be applied if different service life times are desired [15]; The presented method considers the provisions of the revision proposal of EN 1992-1-1, which presents the thickness of the concrete cover depending on the carbonation resistance class (RXC), respectively exposure class (XC) for lifetimes of 50 years and 100 years, respectively (Table 1).

Table 1. Minimum values of the concrete cover thickness 


\begin{tabular}{ccccccc}
\hline $\begin{array}{c}\text { Preliminary } \\
\text { Values }\end{array}$ & \multicolumn{2}{c}{ Minimum values of the concrete cover for service life times of $\mathbf{5 0}$ and $\mathbf{1 0 0}$ years } \\
\hline $\begin{array}{c}\text { Exposure } \\
\text { Classes }\end{array}$ & \multicolumn{2}{c}{ RXC20 } & \multicolumn{2}{c}{ RXC30 } & RXC40 \\
\cline { 2 - 8 } & $\mathbf{5 0}$ years & $\mathbf{1 0 0}$ years & $\mathbf{5 0}$ years & $\mathbf{1 0 0}$ years & $\mathbf{5 0}$ years & $\mathbf{1 0 0}$ years \\
\hline XC1 & 10 & 15 & 10 & 20 & 10 & 20 \\
\hline XC2 & 10 & 15 & 15 & 20 & 25 & 30 \\
\hline XC3 & 15 & 20 & 20 & 25 & 25 & 35 \\
\hline XC4 & 15 & 20 & 20 & 25 & 25 \\
\hline
\end{tabular}

The method aimed to allow direct and practical applicability, based on the next European provisions. In special cases, where different lifetimes are desired, probabilistic methods can be used [15].

2. Establishing the performance of the concrete. Regarding performance, it can be considered by taking into account the functionality of the construction. In this article, the performance will be established for the compressive strength of the concrete and the depth of carbonation. Different types of cements and formulations will be used to reach the same performance levels;

3. For the different component materials and formulations, but for the same levels of performance and service life it will be possible to determine the environmental impact, thus allowing to select the formulation with the lowest environmental impact.

\section{Application of the method}

\subsection{Service life}

As the method has a practical regulatory applicability, the service life times will be considered 50 or 100 years. Obviously, this approach is possible considering the provisions of the European standards EN 206 [16] and EN 1992-1-1 [17] draft revisions.

\subsection{Determining the carbonation performance of concrete}

\subsubsection{Carbonation Resistance Classes}

\subsubsection{Defining the Carbonation Resistance Class}

The designation of ERCs for resistance against corrosion induced by carbonation ( $\mathrm{RXC}$ ) is derived from the carbonation depth in $\mathrm{mm}$ (characteristic value of $90 \%$ fractile) expected to be obtained after 50 years under reference conditions (400 ppm $\mathrm{CO}_{2}$ in a constant $65 \% \mathrm{RH}$ environment and at $20^{\circ} \mathrm{C}$ ). Referring to a nominal diffusion process, it has the dimension of a carbonation rate ( $\mathrm{mm} / \mathrm{square}$ root of time expressed in years) [4].

In order to determine the carbonation resistance class, the following steps must be completed:

1. Experimental determination of carbonation depth under controlled conditions of temperature, humidity, and $\mathrm{CO} 2$ concentration;

2. Calculation of $\mathrm{Kc}_{\mathrm{c}}$ (carbonation rate) for the ages at which experimental determinations were performed;

3. Calculation of carbonation depth $X_{c}$ at 50 years age $\left(X_{c}=K_{c} \sqrt{t}\right)$;

4. Determining the values of the $\mathrm{W} / \mathrm{C}$ ratios that ensure the achievement of the different carbonation resistance classes (Table 2);

Table 2. Carbonation resistance classes

\begin{tabular}{ccccc}
\hline Preliminary values & \multicolumn{2}{c}{ Carbonation Resistance Classes RXC } \\
& RXC20 & RXC30 & RXC40 & RCX0 \\
\hline $\begin{array}{c}\text { Class definition, carbonation } \\
\text { depth at 50 years [mm] }\end{array}$ & 20 & 30 & 40 & - \\
\hline Standard & & EN 12390-10 [18] \\
\hline Descriptive criteria & & Maximum W/C ratio
\end{tabular}




$?$

?

5. Determining the thickness of the concrete cover layer for reinforcement.

Table 1 presents proposals regarding the values of the carbonation depth depending on the carbonation resistance classes, exposure and structure service life time [17].

3.2.2 Experimental study

For the study and application of the method, the concretes were prepared with two types of cements were chosen:

- $\quad$ CEM II / AM (S-LL) 32,5R manufactured with different percentages of slag and limestone, and

- CEM II / AS 32,5R type, with the following percentages of blending materials:

1. CEM II / A-M (S-LL) 32.5R - slag 10\%, limestone 7\% - furtherly referred as CEM 1 ;

2. CEM II / A-M (S-LL) 32.5R - slag 14\%, limestone $4 \%$ - furtherly referred as CEM 2;

3. CEM II / A-S 32.5R - slag 17\%, limestone 3\% - furtherly referred as CEM 3.

The formulations of concrete were named according to the cement used type - CEM 1 , CEM 2 and CEM 3.

The properties of the fresh concrete were presented to highlight the W/C ratios obtained with similar cement dosages for the same consistence class, to emphasize the performance of the fresh concrete. The $\mathrm{W} / \mathrm{C}$ ratio is an essential parameter for the assessment of strength and durability of concrete.

Different concretes were prepared using these cements, with cement contents between 280 and $470 \mathrm{~kg} / \mathrm{m}^{3}$, aggregates sizes $0-4 \mathrm{~mm}(35 \%), 4-8 \mathrm{~mm}(15 \%), 8-16 \mathrm{~mm}(21 \%)$ and 16-32mm (29\%). - and superplasticizer (dinaphthalmethane-sulfonate base) / hyperplasticizer (polycarboxylate base) admixture.

During the research program, the compressive strengths and the carbonation depths were measured for the concretes with three types of cements, up to the age of 1 year. Cubic samples were used, and the results presented are the average obtained on three samples. The tests were performed according to the provisions of EN 206 [3].

\subsubsection{Properties of fresh concrete}

The concretes were prepared with superplasticizer / hyperplasticizer admixture, at different cement contents, according to Table 3, for slumps between $100-150 \mathrm{~mm}$.

Table 3. Properties of fresh concrete

\begin{tabular}{|c|c|c|c|}
\hline Cement Content $\left(\mathrm{kg} / \mathrm{m}^{3}\right)$ & Slump (mm) & W/C Ratio & Density $\left(\mathrm{kg} / \mathrm{m}^{3}\right)$ \\
\hline \multicolumn{4}{|c|}{ CEM 1, 0,6\% hyper plasticizer admixture } \\
\hline 280 & 125 & 0,61 & 2364 \\
\hline 320 & 125 & 0,49 & 2322 \\
\hline 370 & 120 & 0,43 & 2405 \\
\hline 400 & 120 & 0,40 & 2399 \\
\hline 470 & 115 & 0,37 & 2366 \\
\hline \multicolumn{4}{|c|}{ CEM $2,0,6 \%$ hyper plasticizer admixture } \\
\hline 280 & 120 & 0,58 & 2360 \\
\hline 320 & 120 & 0,50 & 2396 \\
\hline 370 & 125 & 0,43 & 2423 \\
\hline 400 & 120 & 0,40 & 2394 \\
\hline
\end{tabular}




\begin{tabular}{cccc}
\hline 470 & 125 & 0,36 & 2415 \\
\hline & CEM 3, 1\% super plasticizer admixture & \\
\hline 320 & 105 & 0,59 & 2367 \\
\hline 370 & 105 & 0,50 & 2364 \\
\hline 400 & 120 & 0,45 & 2359 \\
\hline 470 & 105 & 0,40 & 2359 \\
\hline
\end{tabular}

3.2.2.2 Properties of hardened concrete

\subsection{Compression resistance}

The values of the compressive strengths for the three types of cements are presented in Figures 2 at the age of 28 days, Figure 3 at the age of 90 days, Figure 4 at the age of 180 days and in Figure 5 at the age of 1 year respectively.

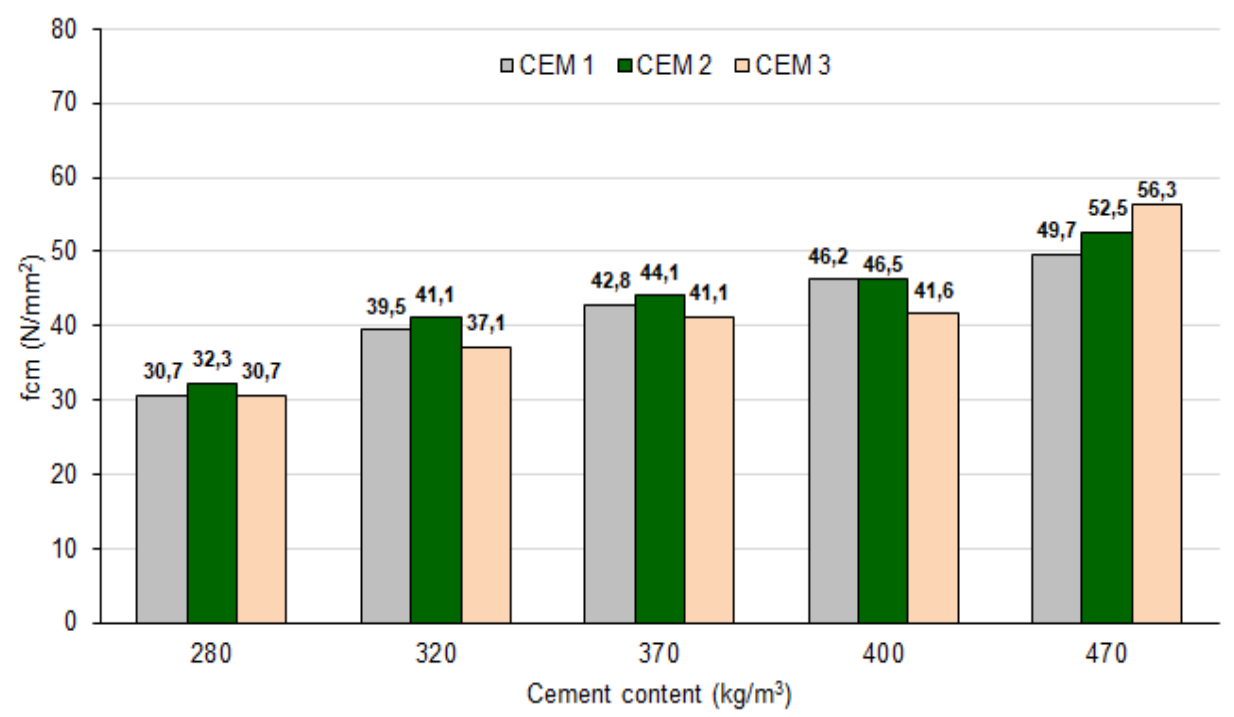

Figure 2. Variation of compressive strengths depending on the cement content at the age of 28 days

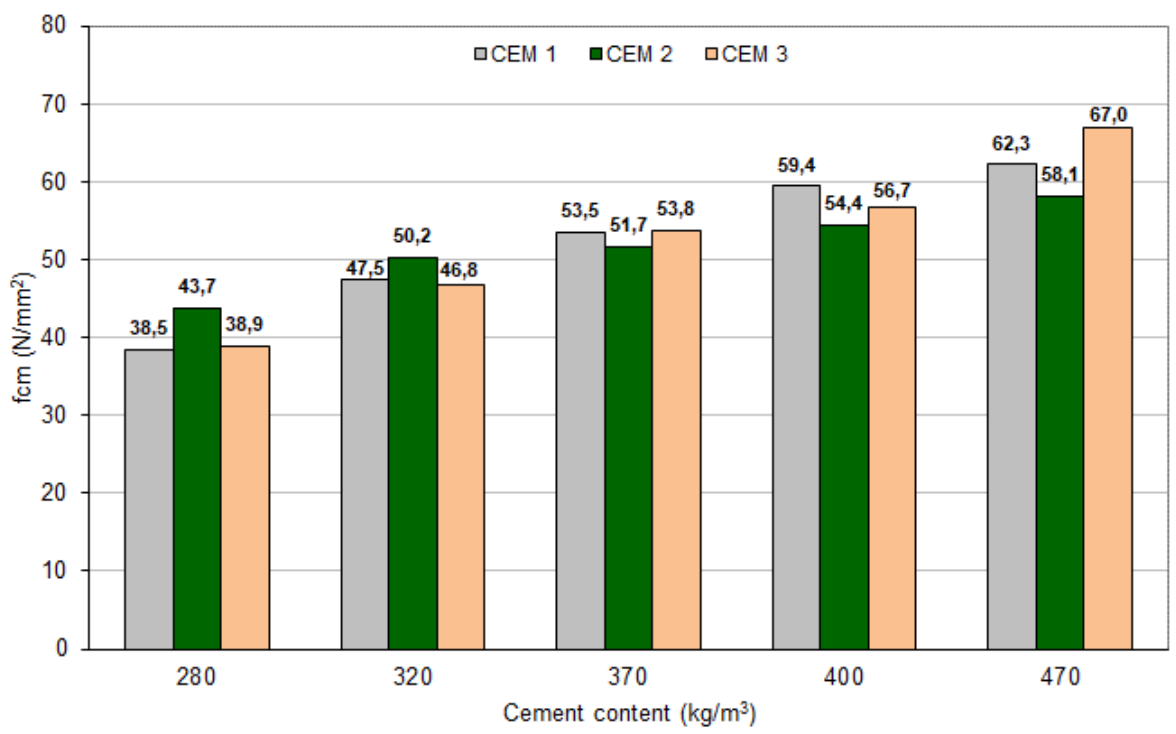

Figure 3. Variation of compressive strengths depending on the cement content, at the age of 90 days 


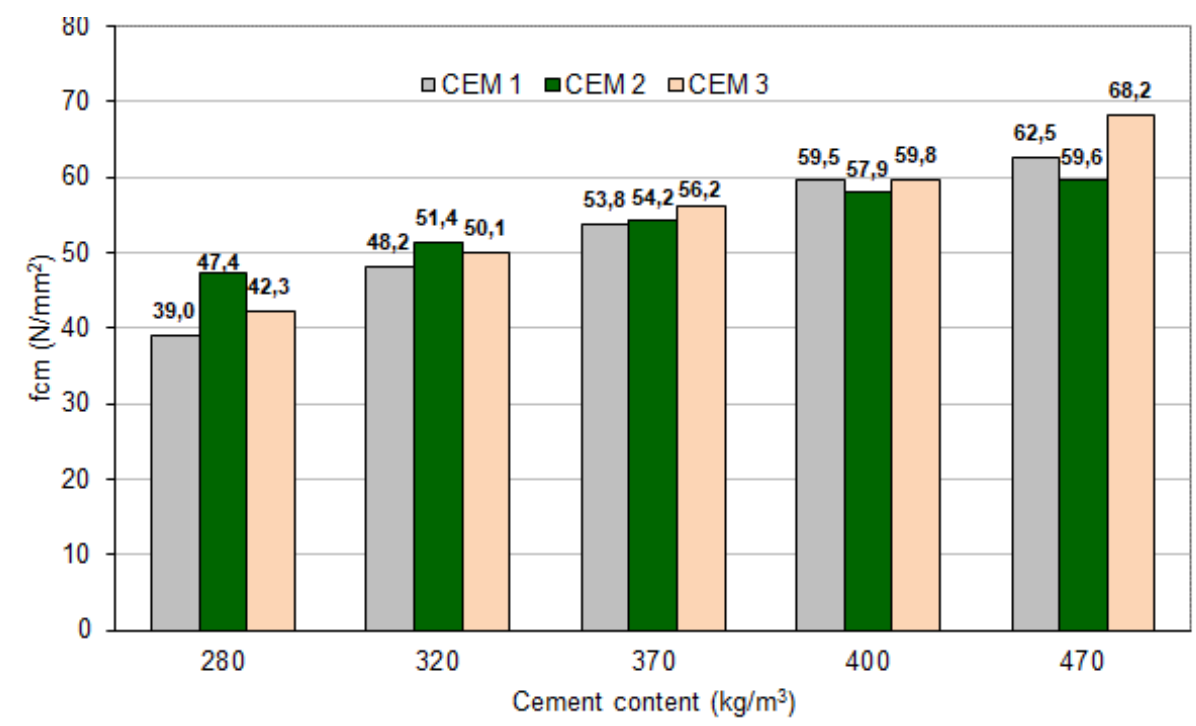

Figure 4. Variation of compressive strengths depending on the cement content, at the age of 180 days

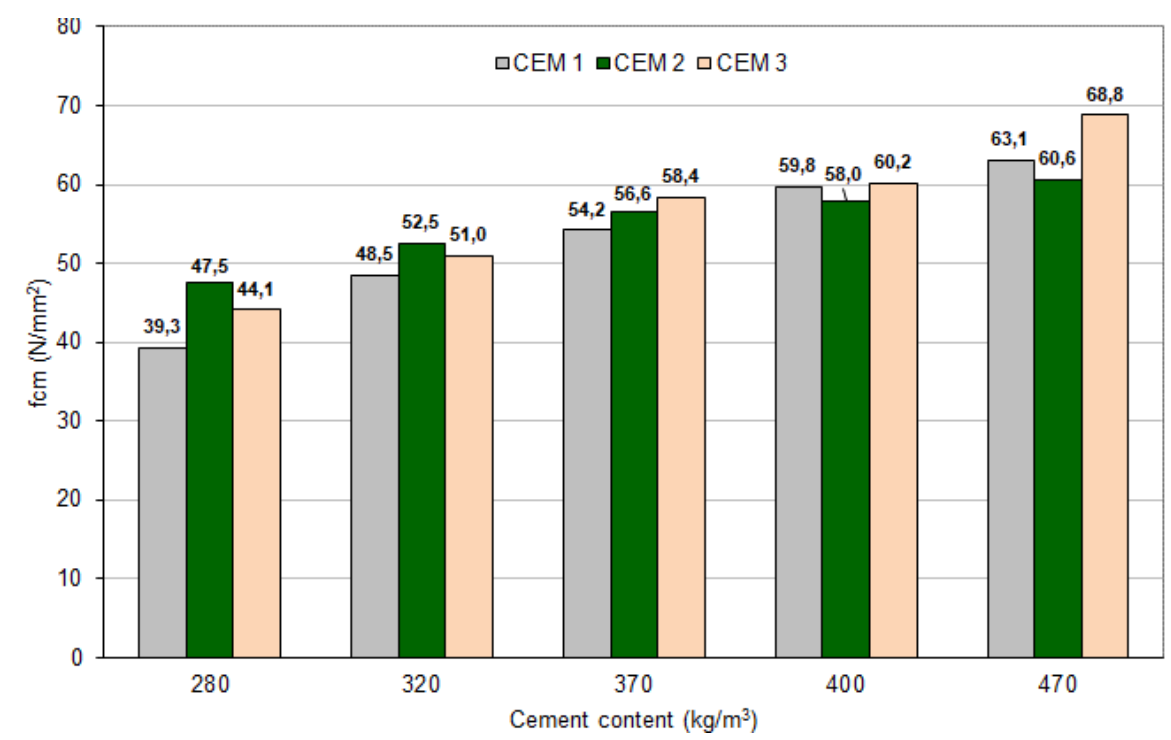

Figure 5. Variation of compressive strengths depending on the cement content, at the age of 1 year

From the presented graphs, some aspects regarding the strength of concrete and its evolution over time can be observed:

- At the age of 28 days, concretes prepared with CEM 2 have higher compressive strengths than concretes prepared with CEM 1 and CEM 3, for cement contents less than or equal to $400 \mathrm{~kg} / \mathrm{m}^{3}$;

- At the age of 90 days, the compressive strengths of concrete prepared with CEM 2 are higher than in other types of concrete, for cement contents less than or equal to $320 \mathrm{~kg} / \mathrm{m}^{3}$. This is also observed at the age of 180 days and 1 year, respectively;

- For high cement contents, of $470 \mathrm{~kg} / \mathrm{m}^{3}$, concretes prepared with CEM 3 have the highest compressive strength for ages greater than or equal to 7 days;

- At the ages of 180 and 365 days, for the cement content of $400 \mathrm{~kg} / \mathrm{m}^{3}$ and the same $\mathrm{W} / \mathrm{C}$ ratio $=0.4$, the compressive strengths are similar for concretes prepared with CEM 1 and CEM 3 and significantly lower for CEM 2.

\subsection{Determination of the carbonation resistance class}

During the research program, measurements of the average carbonation depth were performed, the samples being kept for 7 days in water, then in standardized laboratory conditions (humidity $65 \%$, temperature $20^{\circ} \mathrm{C}$, natural $\mathrm{CO}_{2}$ concentration) up to test age. 
Through these values, the carbonation rates and implicitly the concrete cover thickness of the reinforcement will be calculated.

It should be noted that, generally, the carbonation depths of concrete samples maintained under standardized laboratory conditions are significantly higher than those of samples kept outdoors or in the climatic chamber according to [19] (humidity 65\%, temperature $20^{\circ} \mathrm{C}, \mathrm{CO}_{2}$ concentration $0.4 \%$ ).

In the present study, an example of carbonation resistance classification for samples maintained under standardized laboratory conditions is presented. It will be exemplified in detail for CEM 3 cement type. Figure 6 shows the evolution of the carbonation depth up to the age of 365 days, for different $\mathrm{W} / \mathrm{C}$ ratios. The carbonation rate was determined by calculating the slope of the line fitted through the points with y (carbonation depth) and $x$ (square root of time) coordinates, Figure 7 .

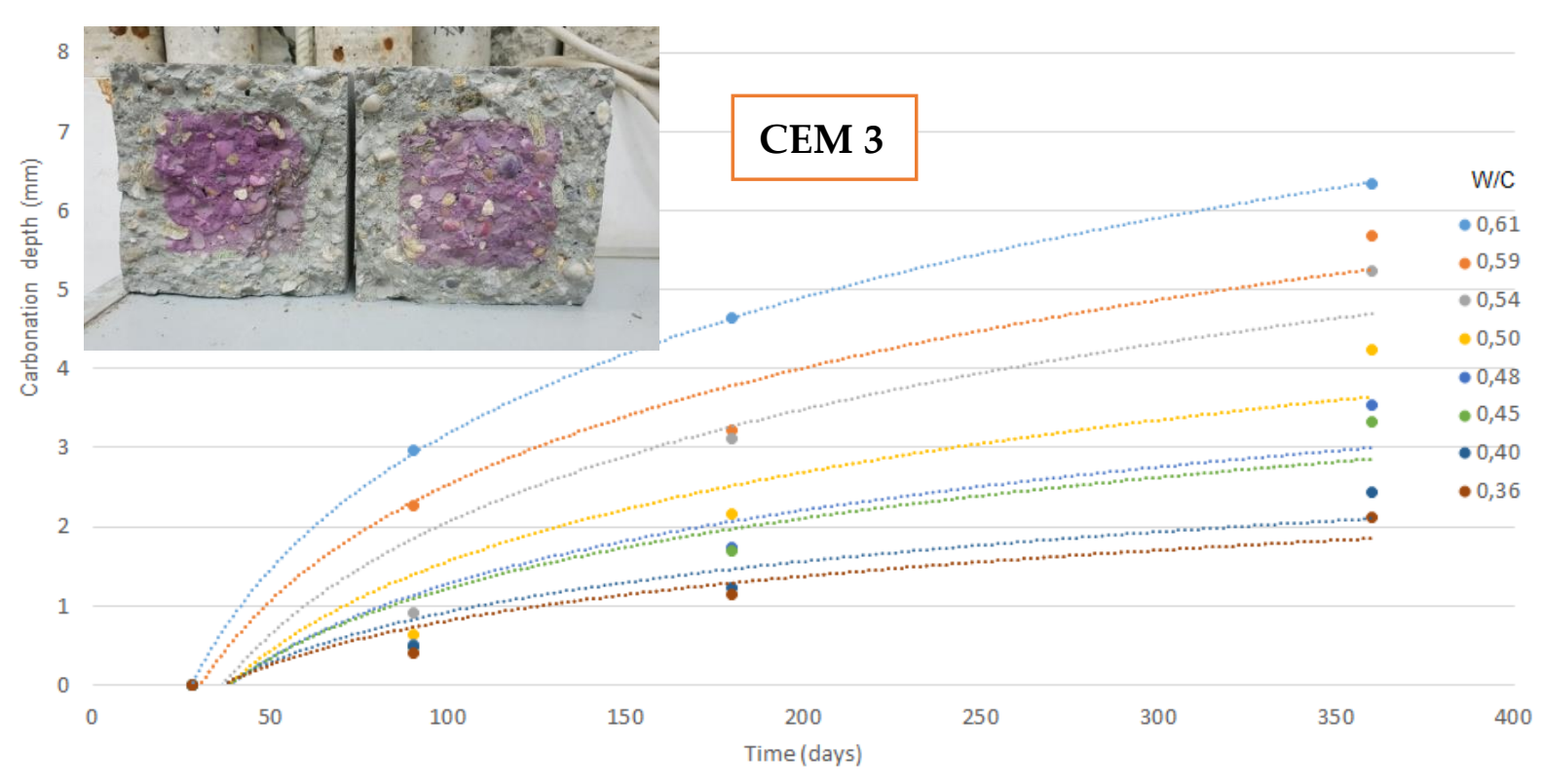

Figure 6. - Evolution of carbonation depth over time

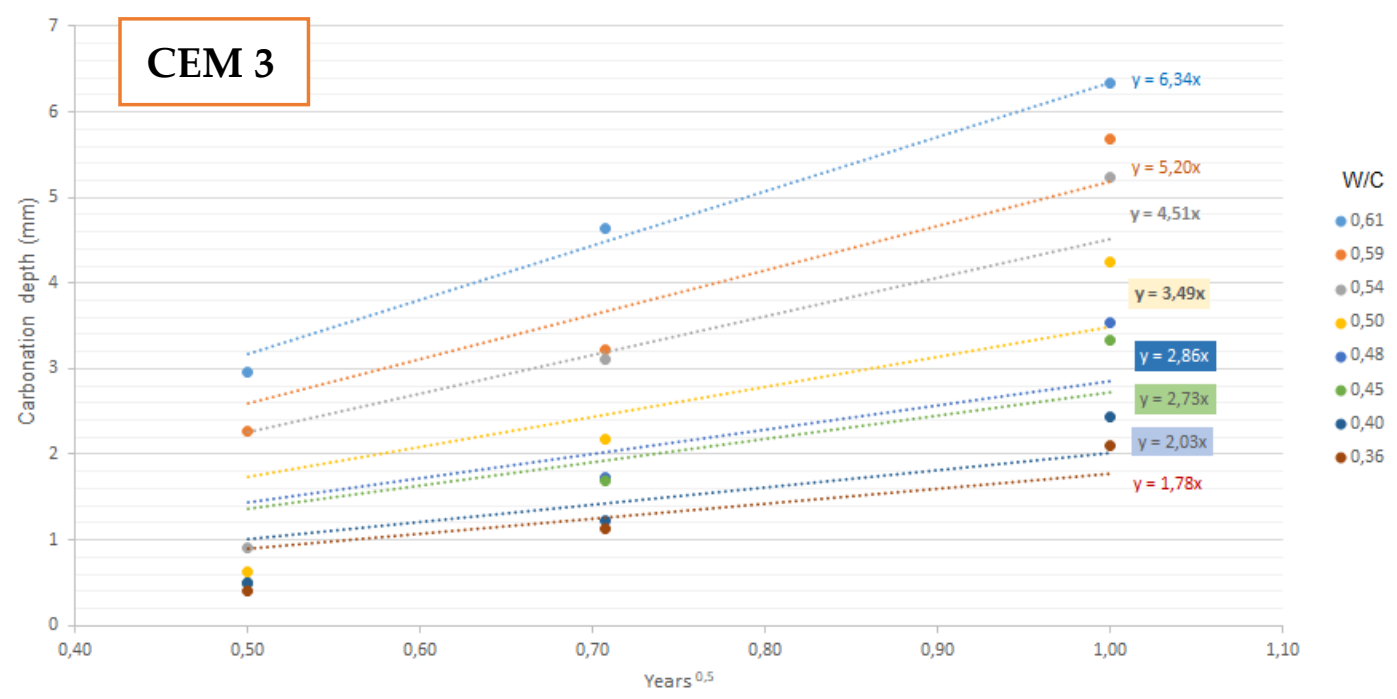

Figure 7. Variation of carbonation depth as a function of the square root of time

In summary, carbonation rates obtained for concretes prepared with CEM 3 cement are presented in Figure 8. 


\section{CEM 3}

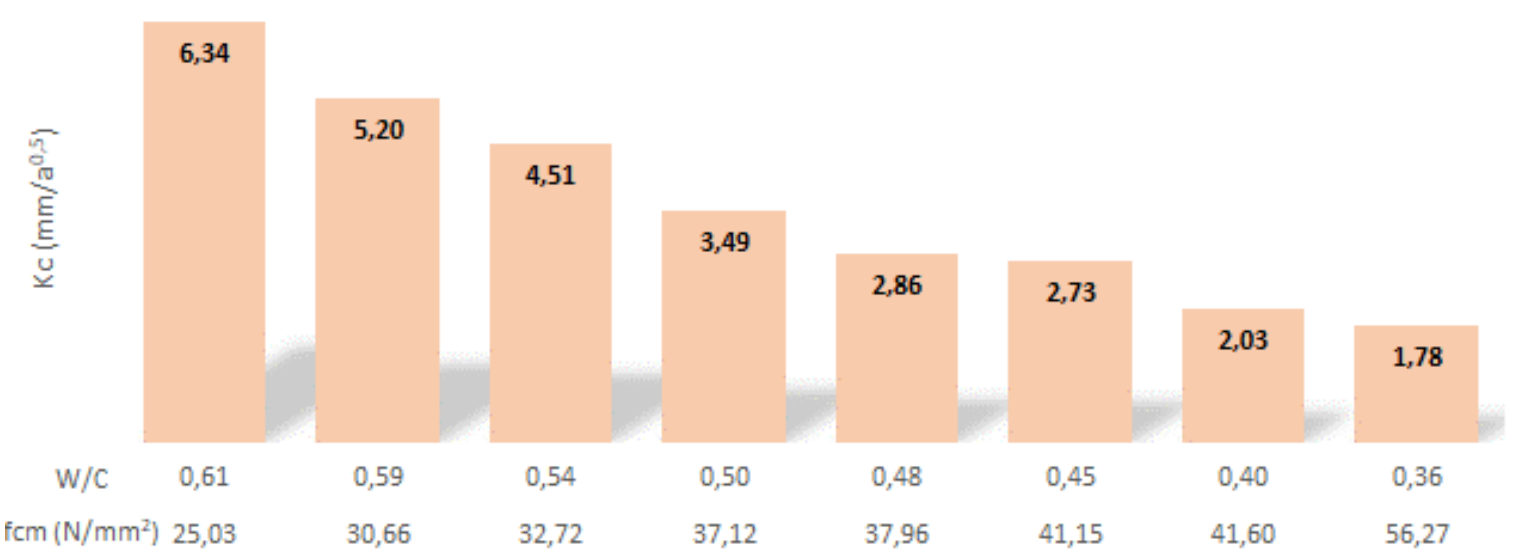

Figure 8. $\mathrm{K}_{\mathrm{c}}$ values depending on the $\mathrm{W} / \mathrm{C}$ ratio and compressive strength at 28 days, for CEM 3

Knowing the coefficient $\mathrm{Kc}$, the carbonation depth can be determined at 50 or 100 years, i.e. the classification in carbonation resistance classes.

The average carbonation depth can be calculated using the equation:

$$
X_{c}=K_{c} \sqrt{t}
$$

where:

$K_{c}=$ carbonation rate, in $\mathrm{mm} /$ years $^{0.5}$

$t=$ effective time, in years

Table 4 shows the carbonation depths at 50 years, calculated according to the values of $K_{c}$ and a proposal of carbonation resistance classification for this type of cement.

A similar approach was applied for the two CEM 1 and CEM 2 cements.

Table 4. Carbonation depth values at 50 years calculated according to Kc values and proposal of carbonation resistance classification

\begin{tabular}{cccc}
\hline W/C & $\begin{array}{c}\mathbf{K c}, \\
\left(\mathbf{m m} / \mathbf{y}^{\mathbf{0 , 5}}\right)\end{array}$ & $\begin{array}{c}\mathbf{X}_{\mathbf{c}} \\
(\mathbf{m m}) / \mathbf{5 0} \text { years }\end{array}$ & RXC proposal \\
\hline 0,61 & 6,34 & 44,83 & RXC50 \\
\hline 0,59 & 5,20 & 36,77 & RXC40 \\
\hline 0,54 & 4,51 & 31,89 & RXC40 \\
\hline 0,50 & 3,49 & 24,68 & RXC30 \\
\hline 0,48 & 2,86 & 20,22 & RXC30 \\
\hline 0,45 & 2,73 & 19,30 & RXC20 \\
\hline 0,40 & 2,03 & 14,35 & RXC20 \\
\hline 0,36 & 1,78 & 12,59 & RXC20 \\
\hline
\end{tabular}

For a series of mixtures using the same blending materials, the carbonation resistance class is determined by plotting the carbonation rate (y-axis) as a function of the $\mathrm{W} / \mathrm{C}$ ratio and fitting the regression line between these points. This line allowed the determination of the $\mathrm{W} / \mathrm{C}$ ratios, rounded to the nearest 0.01 , which give carbonation rates of $2.83,4.24$ and $5.66 \mathrm{~mm} /$ year $^{0.5}$. These $\mathrm{W} / \mathrm{C}$ ratios are the highest that can be used for concretes prepared with the same amounts of blending materials, for carbonation resistance classes RC20, RC30 and RC40 respectively. 
The Figure 9, Figure 10 and Figure 11 show the synthesis of the results obtained for the three cement types in which the performances of the concrete are practically highlighted both from the point of view of the compressive strengths at 28 days and of the carbonation resistances classes. In this case it was considered as a hypothesis, the fact that the concrete is compliant if the carbonation class is equal to or less than RXC 40. Thus, a maximum W/C ratio that allows to achieve a certain equal performance when using different types of cements can be highlighted. Also, if such diagrams are plotted for different cement types using identical blending materials in the concrete formulation, the concrete can theoretically be classified in carbonation resistance classes depending on the compressive strength obtained at 28 days.

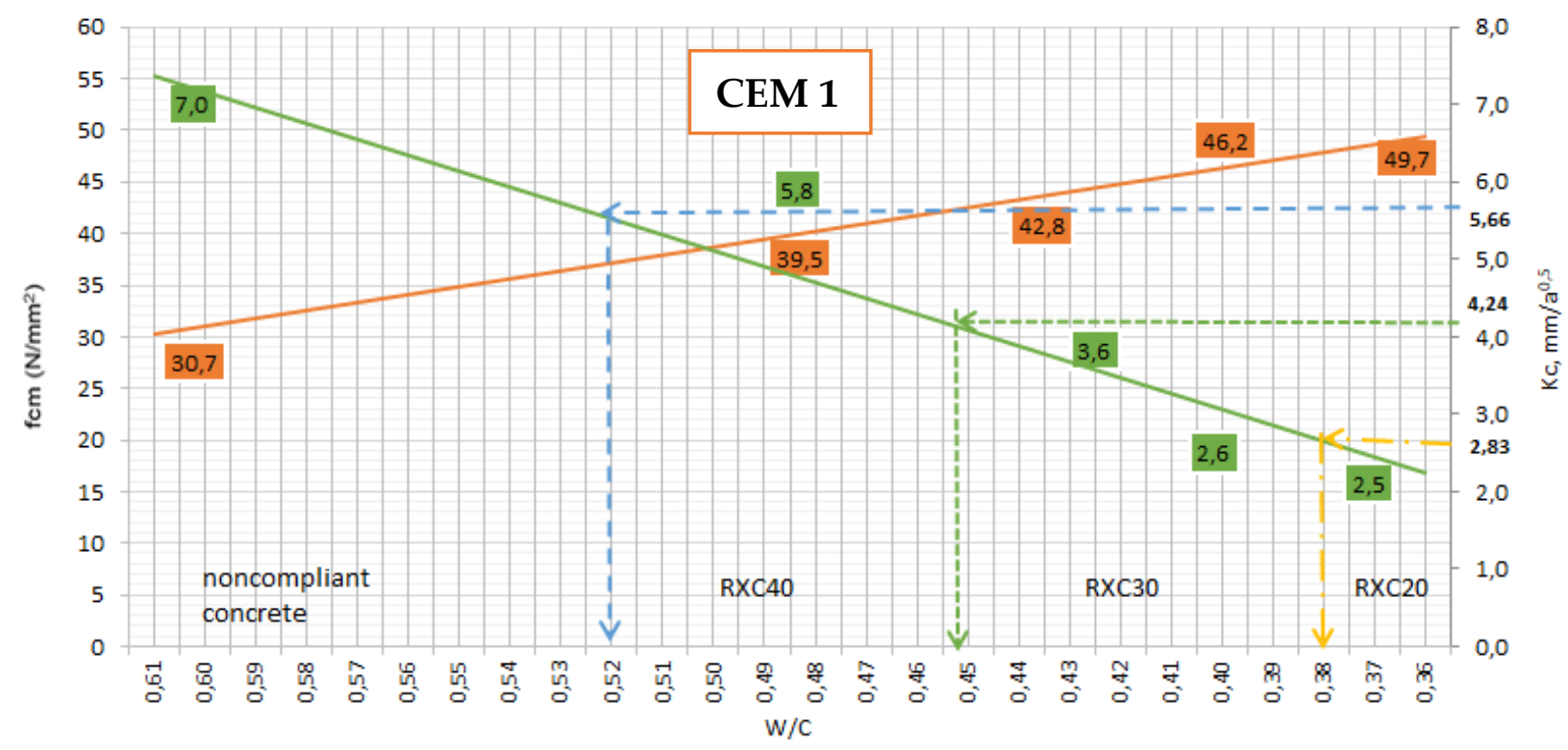

Figure 9. Compressive strengths at 28 days, carbonation rates and classification according to the $\mathrm{W} / \mathrm{C}$ ratios for concretes prepared with CEM 1

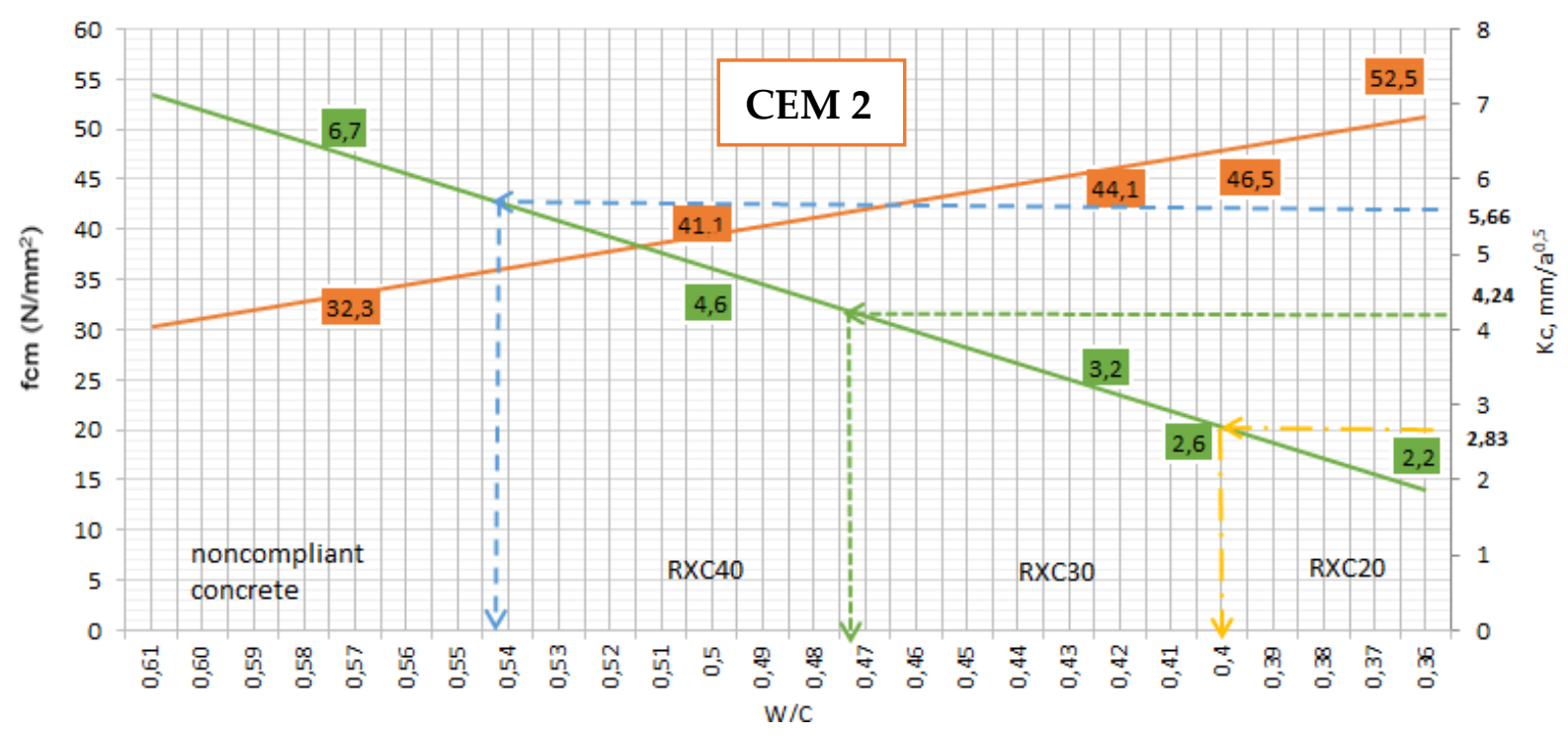

Figure 10. Compressive strengths at 28 days, carbonation rates and classification depending on W/C ratios for concretes prepared with CEM 2 


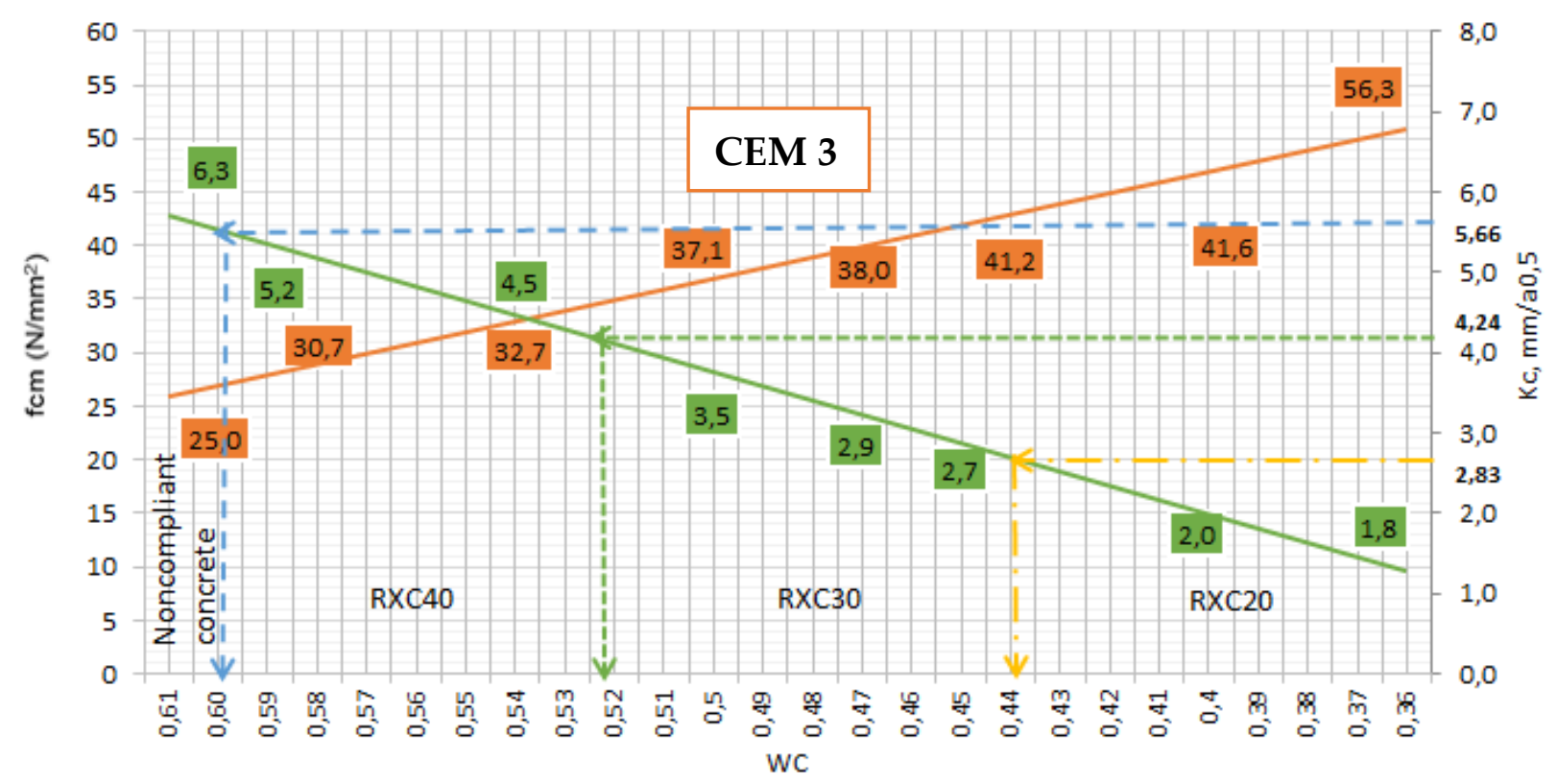

Figure 11. Compressive strengths at 28 days, carbonation rates and classification depending on W/C ratios for concretes prepared with CEM 3

The results obtained from the Figures 9 to 11 are summarized in Table 5. The table shows the maximum $\mathrm{W} / \mathrm{C}$ ratios and cement dosage which permit the concretes prepared with the three types of cements to be included in the RXC20, RXC30 and RXC40 carbonation resistance classes respectively.

Table 5. Maximum W/C ratios and cement dosage of concrete prepared with the three cement types, for the three carbonation resistance classes

\begin{tabular}{ccccc}
\hline \multirow{2}{*}{$\begin{array}{c}\text { Carbonation } \\
\text { resistance class }\end{array}$} & \multirow{2}{*}{$\mathbf{K}_{\mathbf{c}}(\mathbf{m m} / \text { year } 0,5)^{\prime}$} & \multicolumn{2}{c}{ Maximum W/C ratios/cement dosage (kg/m $\mathbf{m}^{\mathbf{3}}$} \\
\cline { 3 - 5 } & 2,83 & CEM 1 & CEM 2 & CEM 3 \\
\hline RXC20 & 4,24 & $0,38 / 460$ & $0,40 / 400$ & $0,44 / 365$ \\
\hline RXC30 & 5,66 & $0,45 / 350$ & $0,47 / 340$ & $0,52 / 320$ \\
\hline RXC40 & $0,52 / 310$ & $0,54 / 300$ & $0,60 / 270$ \\
\hline
\end{tabular}

Table 6 and Figure 12 show a comparison between the revision proposals of EN 19921-1 [17] and EN 206 [16] and the experimental results obtained.

Table 6. Carbonation performance classified by W/C ratio and cement type

\begin{tabular}{ccccccc}
\hline $\begin{array}{c}\text { Carbonation } \\
\text { resistance class }\end{array}$ & $\begin{array}{c}\text { RC2 } \\
\text { (RXC20) }\end{array}$ & $\begin{array}{c}\text { RC3 } \\
\text { (RXC30) }\end{array}$ & $\begin{array}{c}\text { RC4 } \\
\text { (RXC40) }\end{array}$ & $\begin{array}{c}\text { RC5 } \\
\text { (RXC50) }\end{array}$ & $\begin{array}{c}\text { RC6 } \\
\text { (RXC60) }\end{array}$ & $\begin{array}{c}\text { RC7 } \\
\text { (RXC70) }\end{array}$ \\
\hline Cement type & & \multicolumn{7}{c}{ Maximum W/C ratio } \\
\hline CEM 1 & & 0,40 & 0,43 & & 0,49 & 0,61 \\
\hline CEM 2 & 0,40 & 0,43 & 0,50 & & 0,58 \\
\hline CEM 3 & 0,40 & 0,48 & 0,5 & 0,54 & 0,59 & 0,61 \\
\hline CEM II/A-prEN 20 & 0,45 & 0,5 & 0,55 & 0,6 & 0,65 & \\
\hline
\end{tabular}

It is observed that for a $\mathrm{W} / \mathrm{C}$ ratio $=0.5$, the concretes prepared with CEM II / A (EN 206 proposal) and CEM II / A-S - CEM 3, the carbonation resistance class is RC3, while for the other types of concrete prepared with CEM II / A-M, the carbonation resistance class is RC5 (CEM2) and RC6 (CEM1). The differences indicate the different influences of the environment on the cements, as well as the influence of the types and percentages of admixtures. 


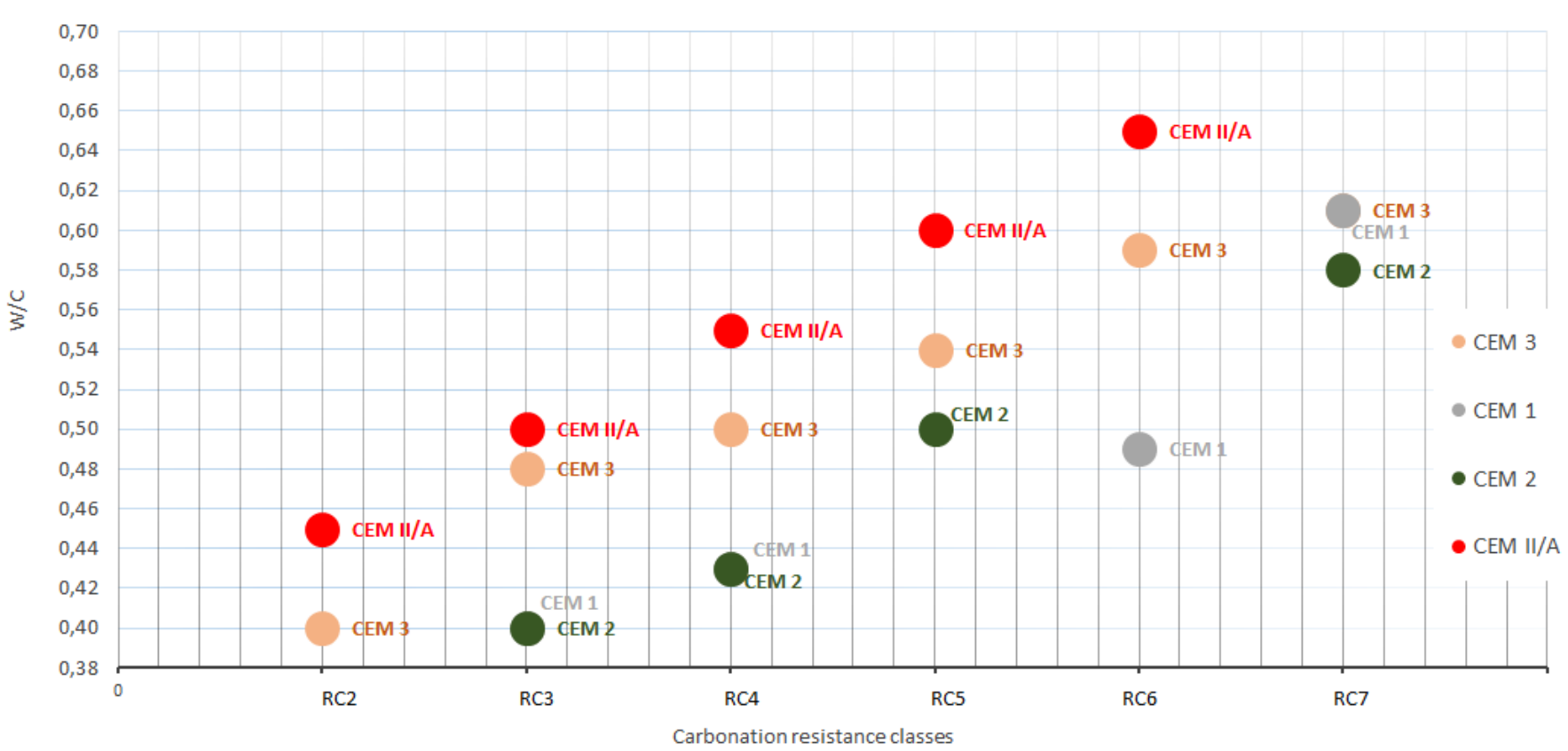

Figure 12. Carbonation resistance classes of concretes prepared with CEM II / A (supplementary proposal EN 206 [9]) and with the three concrete types respectively

The Table 7, Table 8 and Table 9 show the concrete cover for the reinforcements depending on the carbonation resistance classes and the designed service life.

Table 7. Concrete cover thickness depending on carbonation resistance class and W/C ratio, for concretes prepared with CEM1

\section{CEM 1}

\begin{tabular}{ccccccccccc}
\hline \multirow{2}{*}{ W/C } & Exposure class & \multicolumn{2}{c}{ XC1 } & \multicolumn{2}{c}{ XC2 } & \multicolumn{2}{c}{ XC3 } & \multicolumn{2}{c}{ XC4 } \\
\cline { 2 - 11 } & Design service life (years) & $\mathbf{5 0}$ & $\mathbf{1 0 0}$ & $\mathbf{5 0}$ & $\mathbf{1 0 0}$ & $\mathbf{5 0}$ & $\mathbf{1 0 0}$ & $\mathbf{5 0}$ & $\mathbf{1 0 0}$ \\
\hline 0,38 & RXC20 & 10 & 15 & 10 & 15 & 15 & 25 & 15 & 25 \\
\hline 0,45 & RXC30 & 10 & 15 & 15 & 20 & 20 & 30 & 20 & 30 \\
\hline 0,52 & RXC40 & 10 & 20 & 15 & 25 & 25 & 35 & 25 & 40 \\
\hline
\end{tabular}

Table 8. Concrete cover thickness depending on carbonation resistance class and W/C ratio, for concretes prepared with CEM 2

\begin{tabular}{|c|c|c|c|c|c|c|c|c|c|}
\hline \multicolumn{10}{|c|}{ CEM 2} \\
\hline \multirow{2}{*}{$\mathrm{W} / \mathrm{C}$} & \multirow{2}{*}{$\begin{array}{c}\text { Exposure class } \\
\text { Design service life (years) }\end{array}$} & \multicolumn{2}{|c|}{$\mathrm{XC1}$} & \multicolumn{2}{|c|}{$\mathrm{XC2}$} & \multicolumn{2}{|c|}{$\mathrm{XC3}$} & \multicolumn{2}{|c|}{$\mathrm{XC4}$} \\
\hline & & 50 & 100 & 50 & 100 & 50 & 100 & 50 & 100 \\
\hline 0,40 & RXC20 & 10 & 15 & 10 & 15 & 15 & 25 & 15 & 25 \\
\hline 0,47 & RXC30 & 10 & 15 & 15 & 20 & 20 & 30 & 20 & 30 \\
\hline 0,54 & RXC40 & 10 & 20 & 15 & 25 & 25 & 35 & 25 & 40 \\
\hline
\end{tabular}

Table 9. Concrete cover thickness depending on carbonation resistance class and W/C ratio, for concretes prepared with CEM3

\begin{tabular}{|c|c|c|c|c|c|c|c|c|c|}
\hline \multicolumn{10}{|c|}{ CEM 3} \\
\hline \multirow[t]{2}{*}{ W/C } & \multirow{2}{*}{$\begin{array}{c}\text { Exposure class } \\
\text { Design service life (years) }\end{array}$} & \multicolumn{2}{|c|}{ XC1 } & \multicolumn{2}{|c|}{$\mathrm{XC2}$} & \multicolumn{2}{|c|}{ XC3 } & \multicolumn{2}{|c|}{$\mathrm{XC4}$} \\
\hline & & 50 & 100 & 50 & 100 & 50 & 100 & 50 & 100 \\
\hline 0,44 & RXC20 & 10 & 15 & 10 & 15 & 15 & 25 & 15 & 25 \\
\hline 0,52 & RXC30 & 10 & 15 & 15 & 20 & 20 & 30 & 20 & 30 \\
\hline 0,60 & RXC40 & 10 & 20 & 15 & 25 & 25 & 35 & 25 & 40 \\
\hline
\end{tabular}

It is observed that we can obtain the same performance, for example class RC3, for all types of cements tested, but using different $\mathrm{W} / \mathrm{C}$ ratios for the two types of cements $\mathrm{CEM}$ II / A-S 32.5R (CEM 3) and CEM II / A-M 32.5R (CEM 1 and CEM 2) and thus ensure the 
same service life time of 50 or 100 years by providing a certain thickness of concrete cover for the reinforcement depending on the exposure class.

Depending on the amount of materials used, we can move on to the next stage of applying the method, namely establishing the environmental impact.

\subsection{Environmental impact}

The environmental impact assessment is obviously essential for the application of the proposed method. The classification of the impact categories is made according to [12], [20], [21] and are presented in Table 10.

Table 10. Environmental impact categories of industrial processes

\begin{tabular}{ccc}
\hline Category & Designation & Unit \\
\hline CED-fossils & Cumulative Energy Demand (non-renewable) & Joule \\
\hline CED-renewable & Cumulative Energy Demand (renewable) & Joule \\
\hline GWP & Global Warming Potential & $\mathrm{kg} \mathrm{CO}_{2}$ - equivalent \\
\hline ODP & Ozone Depletion Potential & $\mathrm{kg} \mathrm{R}_{\text {- equivalent }}$ \\
\hline AP & Acidification Potential & $\mathrm{kg} \mathrm{SO}_{2}$ - equivalent \\
\hline NP & Nutrification Potential & $\mathrm{Kg} \mathrm{PO}_{4}$ - equivalent \\
\hline POCP & Photochemical Ozone Creation Potential & $\mathrm{Kg} \mathrm{C}_{2} \mathrm{H}_{4}$ - equivalent \\
\hline
\end{tabular}

As indicated in numerous international studies, cement has the most important environmental impact if referred to the other components of concrete, which makes the approach presented in the article even more significant. Of course, one of the most important measures that can be applied is the use of blended cement and aiming not to affect the durability of concrete, basically another measure of sustainability.

All these factors indicated in Table 10 can be calculated, thus indicating the environmental impact of concrete. One of the most important indicators that could be considered in a sustainability analysis for concrete, is the one referring to the global warming potential (GWP). Table 11 shows the GWP values for the materials used in the experimental researches [12] [23].

Table 11. GWP values for cements, aggregates and admixtures

\begin{tabular}{|c|c|}
\hline Cements & $\begin{array}{l}\text { Global Warming Potential, } \\
\text { GWP }[\mathrm{kg} \mathrm{CO} 2 / \mathrm{kg}]\end{array}$ \\
\hline $\begin{array}{l}\text { 1. CEM II/A-M (S-LL) 32.5R slag } \\
10 \% \text {, limestone } 7 \%\end{array}$ & 0.664 \\
\hline $\begin{array}{l}\text { 2. CEM II/A-M (S-LL) 32.5R slag } \\
14 \% \text {, limestone } 4 \%\end{array}$ & 0.662 \\
\hline $\begin{array}{l}\text { 3. CEM II/A (S-LL) 32.5R slag } \\
17 \% \text {, limestone } 3 \%\end{array}$ & 0,661 \\
\hline Aggregates & \\
\hline Sand & $1.06 \cdot 10^{-3}$ \\
\hline Gravel & $1.06 \cdot 10^{-3}$ \\
\hline $\begin{array}{c}\text { Admixtures (superplasticizer, } \\
\text { hyperplasticizer) }\end{array}$ & 0.944 \\
\hline
\end{tabular}

\subsection{Calculation of the sustainability index}

There is a calculation proposal for the sustainability index using the formula [12]:

$$
I_{p s}=\frac{\text { Service Life } \times \text { Performance }}{\text { Environnemental Impact }}
$$


The originality and the simplicity of the proposed method presented in the article consists in the fact that by applying the relation to determine the sustainability index, the first two factors (service life and performance are constant), so that the formula becomes:

$$
I_{p s}=\frac{\text { Constant }}{\text { Environnemental Impact }}
$$

The value of $I_{p s}$ thus depends exclusively on the environmental impact.

Table 12 shows the concrete formulations that allow the same performance (exposure classes) and GWP values, considering the values presented in Table 11.

Table 12. GWP as a function of carbonation resistance class and formulation of concrete

\begin{tabular}{|c|c|c|c|c|}
\hline \multirow{2}{*}{$\begin{array}{l}\text { Carbonation } \\
\text { Resistance } \\
\text { Class }\end{array}$} & \multirow{2}{*}{$\begin{array}{c}\text { Component materials }\left[\mathrm{kg} / \mathrm{m}^{3}\right] \\
\text { and } \\
\text { GWP }\left[\mathrm{kgCO}_{2} / \mathrm{m}^{3}\right]\end{array}$} & \multicolumn{3}{|c|}{ Concrete mix with different Cement type formulation } \\
\hline & & CEM 1 & CEM 2 & CEM3 \\
\hline \multirow[t]{4}{*}{ RXC20 } & Cement & 460 & 400 & 365 \\
\hline & Aggregates & 1727 & 1819 & 1848 \\
\hline & Admixtures & 2.76 & 2.4 & 3.65 \\
\hline & GWP & 310 & 269 & 246 \\
\hline \multirow[t]{4}{*}{ RXC30 } & Cement & 350 & 340 & 320 \\
\hline & Aggregates & 1870 & 1873 & 1875 \\
\hline & Admixtures & 2.1 & 2.04 & 3.3 \\
\hline & GWP & 236 & 229 & 216 \\
\hline \multirow[t]{4}{*}{ RXC40 } & Cement & 310 & 300 & 270 \\
\hline & Aggregates & 1896 & 1902 & 1929 \\
\hline & Admixtures & 1.86 & 1.8 & 2.7 \\
\hline & GWP & 209 & 202 & 183 \\
\hline
\end{tabular}

It can be observed that different component materials and formulations can be used to achieve the same performance of concrete (RXC classes). Obviously, for these different materials and formulations, the environmental impact is different. Actually, the analysis presented showed that concretes prepared with CEM 3 cement have the lowest environmental impact. The constant service life can be ensured considering the thickness of the concrete cover layer presented in Tables 7,8 and 9. Definitely, for the impact calculation, the types of materials used are considered (including the blended cement types), but also the amounts needed to ensure the same performance.

\section{Conclusions}

This article aimed for a simplified method to assess the sustainability of concrete with practical applicability based on the future provisions of standards for the specification, performance, production of concrete and design of concrete elements.

The method considers the performance, service lifetime and environmental impact in order to determine the sustainability index.

The originality of the method consists in the fact that the performance and the lifetime are constant, and the choice of the materials can be done according to the GWP.

The method was applied considering the carbonation resistance as a performance criterion, by performing experimental assessments on concretes prepared with different cement types and amounts of additions. It was thus demonstrated that in order to reduce the environmental impact, a certain formulation/cement type with the lowest GWP can be selected, while ensuring the same performance and service lifetime. In the present experimental study, this is the formulation with CEM 3 cement.

The application of this method was based on the determination of carbonation resistance classes, and can be extended to other actions, e.g. the chlorides or freeze-thaw.

The method would allow the use of materials with a lower environmental impact, especially blended cements, without affecting in any way concrete performance or lead to a service life time reduction of reinforced concrete elements and structures. 
Sustainability must be an important requirement for reinforced concrete structures in the future.

\section{Acknowledgements}

Funding for this research was ensured by the Ministry of National Education (MEN) under grant number UTCB-CDI-2021-019. This support is gratefully acknowledged.

\section{Bibliography}

1. Indra Morandín-Ahuerma; Armando Contreras-Hernández; Dante Ariel Ayala-Ortiz and Octavio Pérez-Maqueo. Socio-Ecosystemic Sustainability. MDPI, Sustainability 17 June 2019

2. Ministry of Development, Public Works and Administration - Law no. 10, the building-quality law

3. EN 206 - Concrete - Part 1: Specification, performance, production and conformity

4. Steinar Leivestad Convenor, "Durability Exposure Resistance Classes, a new system to specify durability în EN 206 and EN 1992, JWG Durability JWG 250/104 - N27", 2017

5. STEINAR LEIVESTAD - “Durability, Concrete, Environment and Sustainability în the Eurocodes”, 02.05.2019, Standard Norge

6. JWG TC104/SC1-TC250/SC2 N26, Exposure resistance classes - draft for proposal on a new system to specify durability in EN 206 and EN 1992, technical background documentation, March 2014

7. CEN/TC 250/ SC 2/WG 1 N 912 - New ERC Concept, National Freedom

8. Federal Ministry for the Environment, Nature Conservation, Building and Nuclear Safety (BMUB) Public Relations Division . 11055 Berlin · Germany Federal Ministry for the Environment, Nature Conservation, Building and Nuclear Safety-Guideline for Sustainable Building Edited by BMUB, Division B I 5 - Civil Engineering, Sustainable Construction, Building Research

9. Ben Stubb Plain English Guide to Sustainable Construction-Constructing Excellence, Warwick House, 25 Buckingham Palace Road, London SW1W 0PP

10. Building Research Establishment Environmental Assessment Methodology. www.bream.com

11. DGNB: (2015): DGNB System, Kriterium, Pro 2.1, Baustelle/Bauprozess

12. Harald S. Müller; Raphael Breiner; Jack S. Moffatt; Michael Haist. Design and properties of sustainable concrete. 2nd International Conference on Sustainable Civil Engineering Structures and Construction Materials 2014 (SCESCM 2014). Procedia Engineering 95 (2014) 290 - 304

13. Harald S. Müller; Michael Haist; Jack S. Moffatt; Raphael Breiner; Design, material properties and structural performance of sustainable concrete. Sustainable Civil Engineering Structures and Construction Materials 2016 (SCESCM 2016). Procedia Engineering 171 (2017) $22-32$

14. Kassiani Tsimplokoukou; Marco Lamperti; Paolo Negro. Building Design for Safety and Sustainability. JRC SCIENCE AND POLICY REPORTS. 2014

15. International Federation for Structural Concrete (2006): Model Code for Service Life Design. fib bulletin 34, Lausanne, Switzerland.

16. CEN/TC 104/SC 1/WG 1 N 237. Draft 4 Working Draft of EN 206 - Part 100 Exposure Resistance Classes.

17. CEN/TC 104/SC 1/WG 1 N 237. prEN 1992-1-1:2021-09

18. EN 12390-10:2018. Determination of the carbonation resistance of concrete at atmospheric levels of carbon dioxide.

19. EN 14630:2006. Products and systems for the protection and repair of concrete structures - Test methods Determination of carbonation depth in hardened concrete by the phenolphthalein method

20. EN ISO 14040:2006. Environmental management - Life cycle assessment - Principles and framework

21. EN ISO 14044:2006. Environmental management - Life cycle assessment - Requirements and guidelines

22. Jane Anderson; Alice Moncaster. Embodied carbon of concrete in buildings, Part 1: analysis of published EPD. Buildings and Cities 1(1): 198-216. June 2020

23. EN 15804:2012-04: Sustainability of construction works - Environmental product declarations - Core rules for the product category of construction products 